\title{
Integrating Computer Applications Into Economics Electives
}

Ann L. Owen

Hamilton College, New York, USA

\begin{abstract}
Typically, undergraduate economics electives focus on content rather than methods, in spite of the fact that empirical work is fundamental to the practice of economics. This article describes an alternative approach to teaching content by using computer applications that emphasise the empirical testing or applications of the theory. Students enjoy economics courses more when they are taught in this way and lab assignments provide opportunities to teach a broad skill set that is important to many undergraduate economics majors.
\end{abstract}

In spite of persuasive arguments in favour of moving away from lecture/exam formats for undergraduate economics classes, the vast majority of economics classes are still taught in the 'chalk-and-talk' format.' Some classes, most commonly statistics or econometrics, have an add-on laboratory component in which students do engage in active learning of statistical techniques, while a few economics programmes contain separate, stand-alone laboratory courses. In contrast, electives in an economics curriculum typically focus on content, rather than empirical methods.

The important feature of all these approaches is that the manner in which content is usually taught in an economics elective is divorced from what students learn in their methods classes. This article describes an alternative approach that uses computer applications that integrate content and empirical methods. This approach attempts to help students develop an understanding of content in a way that more closely resembles the understanding of an empirical research economist.

The economics education literature supports the use of alternative teaching methods. For example, Becker (1997) bemoans the fact that most undergraduate 
economics courses are taught with lecture methods and urges academic economists to adopt more active, hand-on teaching techniques. Salemi (2002) makes a strong case for active involvement of students in the classroom, citing work of educational psychologists and instructional specialists, while Simkins (1999) argues similarly that 'meaningful learning' requires the student to actively participate in the experience.

While these and many other articles provide evidence for the need for active learning generally, several other articles discuss specifically the use of computer applications or labs in the economics curriculum. King and LaRoe (1991) describe the economics curriculum at Denison University that requires students to take a number of lab courses as part of the economics major and presents some informal evidence about the effectiveness of this departure from the traditional curriculum. The method described in this paper shares many similarities with the approach described in King and LaRoe. However, the exercises described here are slightly more sophisticated and occur within the class, not in a separate lab period. In the same vein, Santos and Lavin (2004) describe a research curriculum that teaches students how to find and chart macroeconomic data, access journal articles and write papers on economic issues.

They present some evidence that this technique helps students achieve 'deep learning'. One final example of the effectiveness of computer applications is found in Kendrick, Mercado and Amman (2006). They provide a series of examples using computational economics that allow students to be creative and become more deeply involved in their own education. With this literature in mind, this paper describes one technique, integrating computer applications, that also encourages active learning in economics electives courses. The second section of this paper describes the overall structure of a lab based course. The third section discusses features of a good lab assignment for an elective class. The fourth section provides benefits and drawbacks of this approach. The fifth section discusses some details of this method applied to a course in economic growth. The sixth section provides some preliminary evaluation of this technique, and the seventh section offers a concluding thought. Example assignments are included in the appendices.

\section{Structure of a lab-based elective}

Although labs play a central role in a lab-based course, they do not need to dominate the class. In my course in economic growth (described in more detail later), students complete four labs during the course of the semester with a partner and then complete one lab by themselves in lieu of a final exam. In total, all five labs count for $25 \%$ of the course grade. In addition, students are assigned a 15 to 20 
page final paper ( $25 \%$ of the course grade) in which they are required to use regression analysis as evidence for at least one of the points made in the paper. In this upper-level elective, students are also given a take-home midterm, which takes the form of a five-page essay ( $20 \%$ of the grade), assigned to give an oral presentation of a journal article (10\%), take two quizzes early in the semester $(5 \%)$ and are given a participation grade (15\%).

Most of the students in the class are accustomed to the lecture/exam format in their economics classes and the quizzes serve the purpose early in the semester to transition them to a format that relies more heavily on papers, presentations and participation (i.e. poor performance on the quizzes signals the need for increased effort). This structure is facilitated by the fact that the class is relatively small, with approximately 20 students. This particular course is taught at a highly selective liberal arts college and the prerequisites include intermediate macroeconomics and microeconomics as well as economic statistics. Instructors with less able or prepared students may wish to substitute additional quizzes, in-class exams or problem sets that rely on the more straightforward textbook material for some of the paper and presentation assignments.

Furthermore, lab assignments can be tailored to the sophistication of the students; assignments can focus more on descriptive statistics and graphing for students who are not familiar with multiple regression anlaysis.

Only five class periods are designated as labs, with the purpose of the lab periods being simply to get the students started on the assignment. The topic of regression analysis does spill over into other class periods in a variety of ways and some modification to traditional lecture notes is required to integrate the lab experience into the course content. First, students often ask questions about the lab in subsequent class periods, especially when the topic of the class is related to their labs. In addition, in order to integrate the labs into the course content, current and previous labs are often referenced in relation to the theory being discussed. The nature of the lecture is also geared towards students who will do empirical work as some time is spent discussing the empirical implications of the theory discussed. Furthermore, the articles that students present are carefully selected to include relatively simple but clever empirical strategies that the students explain to their classmates. Finally, econometric issues are discussed in class on an as-needed basis.

Students in the class use the menu-driven STATA, which they learned in their economic statistics class. The class requires access to a computer lab at least five times during the semester. Students work in pairs during the lab period so only one computer for every two students is required. 


\section{Features of a good lab assignment intended to teach theory}

The lab assignments in such a course consist of a small number of open-ended questions that students are required to answer using regression analysis. The nature of economics implies that much of what is taught in economics classes has empirical implications and the key to creating a good assignment is to have students consider the evidence for these implications. The growing availability of free or inexpensive economic data on the Internet makes empirical work possible in almost any economics elective. In designing the assignments, a key principle to keep in mind is that the purpose of the assignments is not to teach econometric methods, nor is it for students to produce irrefutable, publishable results, but to teach the students the content of the elective course. The overarching principle of this method is that it is the process of empirical investigation that generates the learning opportunities. Therefore, the assignments should emphasise the implications of theory discussed in class, rather than the application of a technique of the week' as can happen too often when the focus is on learning statistics.

Depending on the ability levels of the students, the assignments might ask the students to replicate, with explanation, a result in their textbook or in a course reading. This same assignment can be made slightly more difficult by asking the question in a different way than students have seen in course material before. For more sophisticated students, the question could require them to extend material beyond that which was discussed in class. Assignments can also be made more challenging by giving less direction on the data and variables that should be used. In particular, assignments for which students are supposed to use all the data in a data set supplied by the instructor without transformations should be avoided because these kinds of assignments can be completed by students without an understanding of the material.

For example, in a macroeconomics, money and banking, or monetary policy class, students might be given a reading on inflation/output tradeoffs in which estimation of the Phillips curve is discussed. For example, Lansing (2002) provides a discussion accessible to many undergraduates that demonstrates how the slope of the Phillips curve may be different depending on the time period examined. A relatively straightforward assignment would ask the students to reproduce this work with data from different time periods than that used by the author, or different measures of inflation, to confirm that the conclusions are robust. A slightly more difficult assignment might ask the students to read the same article but ask a less directed question, i.e. estimate the cost of a one percentage point decrease in the inflation rate. Of course, to answer this question, the students need to estimate a Phillips curve, but they first need to realise that they do and also to wrestle with the issue of changing slopes. Alternatively, one might be interested in having 
students examine these relationships for a subgroup of the population (e.g. using unemployment rates for teenagers, females, Hispanic males, etc.) and discuss the policy implications of their results.

Finally, an even more challenging assignment might ask students a similar question, but would not provide a reading and would require the students to either reason through an empirical specification based on class discussions or find a relevant article themselves. For students who are inexperienced in using empirical evidence for their ideas, these kinds of assignments are very challenging because the way economics is currently taught does not often require students to consider how to form empirical specifications consistent with their theories. Much of the value in teaching content via labs comes from this very exercise - developing and justifying an empirical specification requires students to think very precisely about their ideas.

A good source for timely and interesting lab questions for a variety of classes can be found in publications intended for a policy-oriented audience (e.g. Fed publications, World Bank publications, many papers written at public policy think tanks). Many of these kinds of articles present empirical analysis that is very accessible to students who have had one statistics class. Two example assignments are shown in Appendix 1 and 2.

The value of asking open-ended questions becomes apparent when the students turn in their lab assignments. Invariably, no two lab reports will be identical. This provides a great opportunity for in-class discussion in which students compare the results of their analysis. In the course of the discussion, the instructor can help students identify the sources of their differences - usually either different theoretical assumptions or different ways of empirically modelling the same assumption. This kind of discussion is a critical step in using this tool as a way of imparting a deeper understanding of the material, and an unavoidable byproduct of this discussion is a better understanding of the methods too. In small classes, this discussion can happen among the entire class. In larger classes, students can be divided into smaller groups and asked to report the conclusions of their comparisons to the larger group.

Opportunities to use this assignment to teach other important skills also exist. For example, writing skills can be practised if lab reports take on the same format as a mini-research paper, starting with an introduction and literature review that would discuss relevant readings and topics from the class. (A sample set of instructions for lab write-ups that require this level of writing is included in Appendix 3.) Oral presentation skills might also be taught with this assignment if students take turns presenting their results to the class. The sophistication of the labs should increase 
over the course of the semester, with a first lab perhaps just generating some descriptive statistics and motivating further work. Depending on the ability levels of the students, the labs can evolve to requiring more subtle ideas and more sophisticated specifications as the semester progresses (e.g. dummy variables, interaction terms, qualitative dependent variables, IV estimation, panel data models). Some of the lab assignments might require students to learn statistical techniques beyond basic multiple regression but the teaching of new statistical techniques in this context should be limited. Ideally, the course would be taught within a programme that allowed students to be exposed to empirical analysis in a variety of electives to make the economics curriculum more cohesive. In such a case, if each course focused on only a few additional techniques, it would be feasible to expose students to a variety of advanced techniques over the course of their undergraduate career. If used in several different classes throughout the economics curriculum, this method might teach students a good bit of the content of an applied econometrics course.

\section{Benefits and drawbacks}

There are many benefits to this approach to teaching undergraduate economics. One of the most important is that students will actually use the techniques they learn in their statistics classes, allowing them to make connections across classes. Even if students are currently using their knowledge of statistics to read material in more advanced courses, as we all know there is a big difference between reading about statistical analysis and doing it yourself. Another important benefit is that lab assignments offer students an alternative way of demonstrating their knowledge other than in-class exams. Diversifying the types of assignments helps the course appeal to students with different learning styles. In addition, the empirical understanding of important concepts gained through these types of assignments is a different kind of understanding than that gained by reading a textbook. Students who are working on lab assignments, even at a rudimentary level, will have a better understanding of assigned readings, including those that use more sophisticated empirical techniques. Thus, this approach complements well the standard way of learning economics.

Lab assignments also lend themselves well to giving assignments at different levels of difficulty. By requiring more sophisticated techniques or ideas, it is relatively easy to increase the difficulty of the assignments as the semester progresses, ensuring that students are challenged throughout the course. Furthermore, the process of considering appropriate empirical evidence for ideas can be quite difficult for students as they typically do not get many opportunities to do this as undergraduates. For those instructors who want to design classes that appeal 
particularly to hard-working and intellectually curious students, this approach is very useful.

Often, these kinds of assignments can help students get started on their own research project. Work initially done as part of an in-class lab assignment, especially one that relies on an open-ended question, can expand and evolve into a student's senior thesis or an independent research project. Realistically, lab assignments in a course will not turn into publishable research, but the exposure to the process can be a valuable and important first step in learning how to do empirical research. For the few students who are contemplating graduate school, lab assignments of this type can give them exposure to the research process that will be helpful to them as they enter an economics PhD programme.

Another benefit of this approach is that it accommodates extensions that facilitate the teaching of other important skills such as writing and speaking. As mentioned earlier, by requiring students to write up their results in a paper or present their results to the class in an oral presentation, students can also be taught writing and speaking skills.

Finally, teaching in this way has personal benefits for the instructor. It often leverages our own expertise as economists; and, for those in environments in which teaching and research is carefully balanced, it encourages a synthesis of the two activities.

Of course, there are drawbacks. The most important are related to additional constraints imposed by this method of teaching. First, in order to keep the course focused on content and not statistical technique, it is important for students to take a statistics course that teaches multiple regression analysis prior to taking the elective. This has the disadvantage of potentially discouraging students from studying economics as it puts another hurdle in front of students interested in the material taught in the elective classes. Also important, however, is the fact that this teaching method potentially requires more resources (i.e. smaller student to faculty ratios as well as reliable computing equipment). Students answering open-ended questions may require more help from instructors. In addition, to the extent that writing or speaking assignments are given in conjunction with the lab assignments, class sizes may need to be reduced to make these components successful as well.

Finally, one must also take into account that by emphasising empirical work, given time constraints, other work may be de-emphasised in class. Instructors can minimise this concern by assigning straightforward parts of the textbook for students to read and learn on their own. This strategy is facilitated by choosing a textbook that is very accessible to the students. 


\section{Details on the assignment: an example from an economic growth class}

Although this teaching technique has a wide application in most fields taught in the undergraduate economics curriculum, this section provides more detail on how this strategy has been implemented in my class on economic growth. This class is an upper-level elective with prerequisites of intermediate micro, intermediate macro and an economic statistics class in which students have been introduced to the concept of multiple regression. In addition to the labs, students in this class are also responsible for reading carefully selected journal articles with empirical components that complement the lab assignments in class. Each of them takes a turn making a 10 to 15 minute presentation of the main points of one article and relating them to previous articles and class discussions. Several of the students in the class are completing a capstone experience for the major and are required to write a final paper that makes a policy recommendation that enhances long-run growth in a specific country and uses regression analysis as supporting evidence for at least one of their points. The labs in the class prepare the students to be able to complete this final assignment, which is one step closer to independent research. An example of the senior project assignment is included in Appendix 4. ${ }^{2}$

The level of econometric sophistication of the students is relatively low at the beginning of the semester. Students generally know how to run multiple regressions, but have not had much practice doing so and have no clear ideas of how to match up theory and evidence. I spend one class at the beginning of the semester reviewing key regression concepts, but most of the learning of statistics methods in this class is accomplished as the students themselves develop a need to know more about methods because they come to understand that they need to use them.

The first lab of the semester is completed within the first two weeks of classes and its purpose is to simply introduce students to the data and some facts about the world distribution of income that motivate many of the topics of the course throughout the semester. I compile one large data set for use in all the labs and make that available to the students. The data set contains about 100 variables compiled from World Bank Development Indicators, Penn World Tables and data made available by authors of journal articles. Although it is true that much of the data for many macroeconomic topics can be found on the Internet, manipulation of that data can be time consuming for the students and it is a much more effective learning experience if the students spend more of their time on analysis.

After the first, mostly descriptive, lab, subsequent labs require students to become more sophisticated in their analysis. The next lab requires students to use multiple 
regression analysis to explain an important growth variable such as investment or education and a third lab might require even more sophistication by requiring students to transform variables or use interaction terms to support their ideas. As might be expected in a course in economic growth, endogeneity and causality are key issues in the journal articles the students are reading, and we do spend some class time discussing the importance of and ways of addressing these issues. The last lab of the semester requires them to address these issues, possibly with instrumental variables estimation.

Each lab is started in class, although students cannot finish them in one class period. I do require that, in the initial lab period, they work with one other person in the class to help them get started, but give them the option to do a joint or independent write-up. In teaching during the actual lab period, it is important to balance the students need for clear direction against the benefit of allowing them to think about questions for which there is not obviously a right answer. I do emphasise to the students that they need to start with their ideas and then work out the empirical implication of these ideas. Although giving them one large data set with many variables reduces the temptation to run hundreds of regressions, the concept that the theory should determine the empirics can be difficult for some students. Much of the teaching during this initial lab period is, in fact, comprised of conversations with the students about exactly what their ideas are.

As students make progress during the lab period, they can be prodded into fruitful directions with leading questions from the instructor. Examples of these kinds of questions include:'Do you think each year of education is equally valuable?','Will the effect be the same in poor countries and rich countries?' or 'Do you think investment in 2000 can affect growth over the 1960 to 2000 time period?'These questions are then followed up with more specific questions about what their answer implies about the empirical specification (e.g. dummy variables, interaction terms, appropriate time lags.) My goal at the end of each lab period is to have every student leave with an understanding of the question they are answering in the lab and the methods they will use to answer it.

\section{Measures of success}

Ideally, to test the effectiveness of this method, one would like to be able to randomly assign students in the same class with the same instructor to a control group and an experimental group in which the students in the experimental group did the additional lab assignments, but the students in the control group did not. However, as explained above, effectively using this technique requires that it be integrated into the entire course and doing so alters slightly how class time is 
spent. Therefore, it is not feasible to have such an experimental design. An alternative way of evaluating the success of this teaching technique is to ask whether or not students enjoyed the course more. This kind of evidence can be found in teaching evaluations. Over the past nine years, I have taught two elective courses, monetary policy and an economic growth class. In some years, the courses were taught in the traditional manner, and in others the courses were taught following the methods described in this paper. All together, there are nine sections, with four being taught in the traditional manner and five being taught using computer applications. Whether taught with or without the labs, all sections were approximately the same size.

Evidence from the narrative part of the course evaluations supports the idea that students enjoyed the course more when the computer applications were included. Although some students admit that they do not like what is perceived to be extra work in this class, almost all of them recognise the value. Students overwhelmingly report on course evaluations that the experience is challenging and rewarding, allowing them to explore ideas outside of the textbook. For example, one student wrote,'I really liked the way the course was designed... we were able to take what we learned and apply it instead of studying just a bunch of graphs.' Another student echoed that sentiment,'The class wasn't simply based on the textbook - we found our own evidence to support the theories.' In contrast, a student in the more traditionally taught course complained that the structure of the course was 'predictable'.

The sentiments expressed in these comments are borne out by a more systematic compilation of ratings of the course. Although the college-wide teaching evaluations do not query the students about their knowledge of economic theory, they do ask the students to rate the overall effectiveness of the course and the teacher. Table 1 summarises the results of the answers to these two questions by the methods used to teach the class.

Table 1: Summary of Course Evaluations by Teaching Method

\begin{tabular}{llll}
\hline & \multicolumn{3}{c}{ Teaching Method } \\
& Traditional & $\begin{array}{l}\text { Integrate } \\
\text { Computer } \\
\text { Applications }\end{array}$ & $\begin{array}{l}\text { p-values for } \\
\text { difference in } \\
\text { means test }\end{array}$ \\
\hline Effective Course & 5.4 & 5.6 & .07 \\
Effective Teacher & 5.5 & 5.7 & .04 \\
Number of Observations & 66 & 76 & \\
\hline
\end{tabular}

Note: Questions asked on a 6 point scale with 6 being the highest rating. 
In both cases, the students in the courses that integrated computer applications rated both the course and the teacher as being more effective, suggesting that, on average, students were more satisfied with the class when computer applications were integrated. Although, the magnitude of the changes is not large, it should be noted that the upper bound of the scale is six, making improvements in the average rating more difficult as the upper bound is approached. This informal evidence from course evaluations points to the conclusion that this method not only causes students to enjoy the course more, but it also actively engages students in the study of economics. Together with the evidence from the economics education literature discussed in the introduction, this suggests that using computer applications is an effective teaching technique.

\section{Conclusion}

This paper has described a way in which lab assignments can be integrated into economics electives. Some evidence has been presented that suggests that students enjoy economics courses more when they are taught in this way and are more actively engaged in the material. Lab assignments also provide opportunities to teach a broad skill set that is important to many undergraduate economics majors. The key feature of these assignments is that their primary purpose is to use empirical methods to teach economic theory.

\section{Appendix 1: Sample lab for a money and banking, monetary policy or macroeconomics elective}

\section{Determinants of inflation expectations}

Expectations play a very important role in determining future economic activity; and, in this lab, you will explore the determinants of inflation expectations.

The data provided includes a measure of inflation expectations from the Philadelphia Fed Survey of Professional Forecasters. The data in the variable called, expinfl, is the one year-ahead forecast of annual inflation by the respondents to this survey. In other words, the data for the 4th quarter of 2005 represents the forecast of annual CPI inflation made for 2005:Q4 in the 4th quarter of 2004.

As you consider the appropriate empirical specification, please be sure to consider the appropriate lags of variables to use in your regression as well as whether the relationships you are testing require you to consider levels or growth rates of your independent variables. 
A thorough write-up will:

- describe the economic theory behind the development of your regression equation

- discuss the importance of expectations in determining economic activity and the importance of these expectations for monetary policy makers

- discuss different theories of expectation formation and the support that your results provide for each.

- evaluate your regression equation and discuss the relative importance of each of the independent variables you use in your regression in influencing expectations.

With the exception of the inflation expectations data, which was obtained from the Philadelphia Fed, all data for this lab was obtained from Economagic.com. Variable labels in the Stata data set provide data definitions.

\section{Appendix 2: Sample lab for a development, economic growth or labour course}

\section{The value of education}

Policy makers often have to make difficult choices about the best way to allocate limited resources. Education is one means of making workers more productive and raising incomes. But, of course, resources spent on education are resources not spent in some other potentially useful way.

In this lab you will help to inform this policy decision by answering the question: what is an extra year of education worth? More specifically: if the average education of the labour force is increased by one year, how much higher can the typical country expect per capita income to be 25 years from now?

In determining how to answer this question, be sure to draw on the growth theory that you have already learned. Discuss your regression specification, the confidence that you have in your results and consider potential omitted variables as well as the direction of causation between your dependent and independent variables.

Keep in mind that your overall objective is to provide information that would be helpful to policy makers. Therefore, be sure to explain your data and methods and include a recommendation in your conclusion. 
Note:This lab is one of several labs written by the author to accompany Weil (2005). More examples of several labs designed for a course in economic growth by the author can be viewed at http://wps.aw.com/aw_weil_econgrowth_1/ $0,9337,1443702-, 00$. html $^{3}$

\section{Appendix 3: Sample write-up instructions for a course that emphasises writing}

All lab reports should contain the following sections.

\section{Executive Summary/Abstract}

In this section you will succinctly state your main findings. Often this section will be only a few sentences, but a reader of this section should be able to determine quickly what you have done and what your conclusions are. This section should be written after the rest of the paper is completed.

\section{Introduction and Literature Review}

In this section, you will introduce the question you are trying to answer or the hypothesis you are testing. You should motivate the reader in this section by explaining the importance of this question. You should also review the current literature related to your question (i.e. the class readings and the textbook) to help to put your work in context.

\section{Data description}

In this section you will describe the source and nature of your data. Often descriptive statistics (e.g. means and standard deviations) are presented as a way of introducing your data.

\section{Analysis}

The analysis section contains the details of your investigation. In this section you should explain your method of analysis. In other words, you should answer the question:Why did you use the techniques you used to answer the question you posed in the introduction? You should also present your results in this section. Often, you will include graphs or tables that summarise your results.

\section{Conclusion}

In the final section of your lab, you should state your main conclusions. You should discuss any important limitations of your analysis, stating what data or information you would have liked to have in order to answer your questions more thoroughly. 


\section{Appendix 4: Sample assignment for a capstone experience}

There are two required parts of this assignment: a research paper and an oral presentation during the last week of classes.

\section{Assignment}

You have been hired as a consultant to the government of a specific country to analyse that country's current prospects for growth and make recommendations for policies that could help to improve that country's growth performance. Your assignment for this class is to prepare a written report and give an oral presentation stating your findings. In writing your report, you can assume that the government officials have taken (and passed!) all the prerequisites for this class. Each of your recommendations must be justified with either economic theory or with some empirical evidence that you supply (i.e. you need to run a regression.) At least one of your recommendations must be supported by theory and at least one must be supported by theory and empirical evidence. (You may have as many as four or five recommendations in total.) You should also use the results of economics journal articles to support your points.

\section{Choosing a country}

You must choose a country by [date to be arranged]. Nobody may choose to study the United States. To ensure that everybody learns something from your presentation, each senior project student must choose a different country, preferably in different regions of the world (e.g. Latin America, East Asia, SubSaharan Africa, Europe, Former Soviet Bloc countries, North America). Countries will be assigned on a first-come/first-serve basis. Prior to selecting your country, I highly recommend that you do some preliminary reading to make sure that the issues facing your country are of interest to you. Two sources of country-specific information are the International Monetary Fund and the World Bank (see links on this course's home page). The staff of the International Monetary Fund periodically prepares Country Reports that give detailed information on many countries. (Go to the IMF website, click on publications and then search on IMF Staff Country Reports to see a list of the reports available. Many can be downloaded from the Internet immediately, but some are only available in hard copy, and obtaining them involves both a fee and a delay.) 


\section{Guidelines}

Your paper should be approximately 15 pages in length (excluding exhibits). However, its length may vary slightly from this number, depending on the issues you discuss. However, if you find that your paper is less than 14 pages, you should reconsider whether or not you have covered the topic thoroughly. Under no circumstances should you write a paper that is longer than 20 pages.

The oral presentation should last between 15 and 20 minutes. Presentations that are longer than 20 minutes will be stopped before they are completed.

\section{References}

Becker, William E. (1997) 'Teaching Economics to Undergraduates', Journal of Economic Literature, 35: 1347-73.

Becker, William E. and Watts, Michael (2001) 'Teaching Methods in U.S. Undergraduate Economics Courses', Journal of Economic Education, 32(3): 269-279.

Kendrick, David A., Mercado, P. Ruben and Amman, Hans M. (2006) 'Computational Economics: Help for the Underestimated Undergraduate', Computational Economics 27(2-3): 261-271.

King, Paul G., and Ross M. Laroe (1991) 'The Laboratory-Based Economics Curriculum', Journal of Economic Education 22(3): 285-92.

Lansing, Kevin J. (2002) 'Can the Phillips Curve Help Forecast Inflation?' Federal Reserve Bank of San Francisco Economic Letter, Number 2002-29.

Salemi, Michael K. (2002) 'An Illustrated Case for Active Learning', Southern Economic Journal, 68(3): 72131.

Santos, Joseph and Lavin, Angeline M. (2004) ‘Do as I Do, Not as I Say: Assessing Outcomes When Students Think Like Economists', Journal of Economic Education, 35(2): 148-61.

Simkins, Scott P. (1999) 'Promoting Active Student Learning using the World Wide Web in Economics Courses', Journal of Economic Education, 30(3): 278-87.

Weil, David N. (2005) Economic Growth. New York: Pearson Addison Wesley.

\section{Notes}

1 See Becker and Watts (2001) for a survey of teaching methods in undergraduate economics courses.

2 The students who are enrolled in the class but not completing the senior project do an alternative, less rigorous assignment.

3' Exhibit B', found on the website http://wps.aw.com/aw_weil_econgrowth_1/ $0,9337,1443702-, 00 . h t m l$, the online accompaniment to the text Weil, Economic Growth, copyright 2005 Pearson Education, Inc. Reprinted by permission of Pearson Education, Inc., publishing as Pearson Addison Wesley. All rights reserved. 
International Review of Economics Education

\section{Acknowledgements}

Elizabeth Jensen and Jeffrey Pliskin provided helpful comments.

\section{Contact details}

Ann L. Owen

Hamilton College

198 College Hill Road, Clinton

New York 13323

Tel: $\quad$ 315-859-4419, Fax:315-859-4477

Email: aowen@hamilton.edu 